\title{
Can constructed wetlands be more land efficient than centralized wastewater treatment systems? A case study based on direct and \\ indirect land use
}

Ying Fan ${ }^{\mathrm{a}, 1}$, Xudong $\mathrm{Wu}^{\mathrm{a}, \mathrm{b}, 1}$, Ling Shao ${ }^{\mathrm{c}}$, Mengyao Han ${ }^{\mathrm{d}}$, Bin Chen ${ }^{\mathrm{b}}$, Jing Meng ${ }^{\mathrm{e}}$, Ping Wang ${ }^{\mathrm{a},{ }^{*}}$, Guoqian Chen ${ }^{\mathrm{b}, *}$

${ }^{a}$ School of Soil and Water Conservation, Beijing Forestry University, Beijing 100083, China

b Laboratory of Systems Ecology and Sustainability Science, College of Engineering, Peking University, Beijing 100871, China

${ }^{c}$ School of Humanities and Economic Management, China University of Geosciences, Beijing 100083, China

${ }^{\mathrm{d}}$ Institute of Geographic Sciences and Natural Resources Research, Chinese Academy of Sciences, Beijing 100101, China

e Department of Land Economics, University of Cambridge, Cambridge CB3 9DT, UK

\section{Abstract}

Compared with centralized wastewater treatment systems, constructed wetlands are generally regarded as not suitable for wide deployment due to the comparatively larger direct land area. Much of the traditional thinking is based on an onsite perspective, while the offsite information is left out. By a comparative case study with systems accounting of both onsite and offsite land use, this study questioned the traditional picture and found that constructed wetlands can be more land use efficient than centralized wastewater treatment systems. On a unit of wastewater treated basis, the land use induced by a typical constructed wetland in China is revealed to be less than half of that by the case of a centralized wastewater treatment plant or a hybrid system. On a unit removal basis for biological oxygen demand $\left(\mathrm{BOD}_{5}\right)$, chemical oxygen demand (COD), total suspended solid (TSS) and ammonia-nitrogen $\left(\mathrm{NH}_{3}-\mathrm{N}\right)$, the land use induced by a constructed wetland is only around $61 \%, 67 \%, 73 \%$ and $64 \%$ of that by a centralized wastewater treatment system, respectively. Meanwhile, the indirect effect is demonstrated to be significant for these three systems: this magnitude

\footnotetext{
${ }^{1}$ These authors contributed equally to this work. *Corresponding author.

Email address: wangping@pku.edu.cn,wangp@bjfu.edu.cn (Ping Wang); gqchen@pku.edu.cn (Guoqian Chen).
} 
amounts to three times the direct land occupation for a constructed wetland, and one order of magnitude higher of that for the a centralized wastewater treatment system. By a scenario analysis for China in 2017, it is preliminarily estimated that over two billion square meters of land use could be reduced if all the centralized wastewater treatment systems are replaced by constructed wetlands. The outcome may serve a benchmark and offers a new way of thinking for management of wastewater treatment systems.

Keywords: Constructed wetland; wastewater treatment; land use; systems process analysis

\section{Introduction}

Wastewater treatment plays a crucial role in the construction and development of cities. Historically, as cities grew and natural wetlands failed to treat increased wastewater, the new cities' industrial technologies evolved using tanks, pumps and chemicals to solve the problem. Because city land is valuable, the processing sites, even including the large surface area of the tanks, was constricted to be more like an industrial factory than a spread-out, natural wetlands. Only later was there a move to attempt to plan and construct wetlands as a solution to city wastewater. This paper analyses the differences between centralized wastewater treatment systems (WTSs) and constructed wetlands (CWs).

CWs are artificial engineered systems and designed in a way similar to natural wetlands for treating municipal wastewater. Physical, chemical and biological synergies of substrate, plants and microorganisms serve for treatment of organic, inorganic as well as excess nutrient contaminants when the wastewater goes through CWs in a controlled way through manual design and supervision (Eifert, 1999; Wang and Chen, 2016, 2017; Wang and Zeng, 2019; Wengrzynek, 1991). 
CWs were used experimentally in Germany early in 1952 to treat domestic wastewater in rural areas (Seidel, 1955). Soon afterwards, in 1960s the full-scale engineered wetland system came into use for the first time and thereafter rapidly spread to the rest of the world. In 1972 , the United States witnessed the birth of the first domestic constructed wetland (CW) built at Vermontville, Michigan (Brown, 1994). In subsequent years, other nations and regions also witnessed the appearance of such kind of $\mathrm{CW}$ systems ranging from pilot-scale projects in Portugal (Amaral et al., 2013) to an increasing quantity of commercial-scale CW projects in Italy (Masi et al., 2017), France (Pálfy et al., 2017) and the United States (Tao et al., 2014). As for China characterized with a rapid progress of urbanization and industrialization in recent decades, the $\mathrm{CW}$ has also been highlighted as a promising alternative to cope with the over-consumption and degradation of water resources, especially in suburb areas of smalland medium-size cities. The first reed bed wetland in China was launched by Tianjin Environmental Protection Research Institute in 1987 (Liu, 2017). Later in 1990, Bainikeng Constructed Wetland, the first full-scale CW project in medium-scale municipalities in China for wastewater treatment and located at Shenzhen Special Economic Zone, appeared. By 2015 there were at least $791 \mathrm{CWs}$ for urban and rural wastewater treatment in China (Li, 2018).

Compared with centralized WTSs, CWs have many advantages in terms of strong feasibility of technology implementation, little secondary pollution and environmental impacts, low costs of management during construction and operation, representing landscape elements thus providing social values. Furthermore, these factors are of great significance in terms of hydrology, biogeochemistry and the maintenance of biological habitats and food webs (Richardson, 1994; Vymazal, 2005). According to the 13th Five-Year Plan for the 
Construction of Urban Wastewater Treatment and Recycling Facilities jointly formulated by the National Development and Reform Commission (NDRC) and the Ministry of Housing and Urban-Rural Development of the People's Republic of China (MOHURD), it is suggested that priority should be given to the wastewater treatment schemes (such as CWs) with large water yield, feasible technology, low comprehensive cost, significant economic and social benefits to provide reclaimed water for industry, green irrigation and urban miscellaneous use. What deserves our attention is that it has been continuously pointed out in existing works that CWs are more advantageous in rural areas with low population density, while typical centralized WTSs are more suitable for cities with high population density, mainly due to the large onsite area required for CWs projects (Kivaisi, 2001; Lu et al., 2016; Merlin et al., 2002; Otterpohl et al., 2004; Parkinson and Tayler, 2003; Wu et al., 2011; Ye and Li, 2009).

A major obstacle to the wide deployment of CWs is that the direct land occupation of CWs is much larger than that of centralized WTSs. However, an onsite perspective usually includes only the onsite information but fails to incorporate the offsite information, namely the land use indirectly required by construction, operation, and maintenance of the wetland system. For instance, a CW needs a number of inputs such as substrates, plants and pipes, the production of which will directly and indirectly induce a certain amount of land use. In other words, extra land use is induced in upstream processes to provide the material, machinery and service inputs required by the CW. Just as noted by Lave et al. (1995), the indirect effects could be significant, which may sometimes surpass the direct resource use or emissions. As previously mentioned, $\mathrm{CW}$ bears a resemblance to natural wetland system and resorts to physical, chemical and biological synergies of soil, plants and microorganisms to treat 
wastewater. While for the centralized wastewater treatment system (WTS), it is a purely artificial system and requires lots of external inputs, such as the chemical compounds, machinery, corresponding building works and service inputs, to deal with the contaminants. As a result, the indirect impact on land use of centralized WTSs may be much more significant than that of CWs. Consequently, to give an objective comparison of the centralized wastewater systems and CWs in terms of land use, attention should be paid not only to direct land occupation during the treatment process, but also the land use induced for the production of energy and materials as well as other inputs to reflect the overall land use induced in the different stages.

Academic efforts have been made to compare the environmental impact induced by CWs and that by centralized WTSs based on a life cycle approach. Through solar emergy analysis, Zhou et al., (2009) revealed that CWs were environment-benign and less emergy-intensive despite the relatively low ecological waste removal efficiency compared with the centralized WTSs. This study was inspired by the Odum H.T. and Mitsch W.J. investigation of the embodied energy and solar equivalents of materials used to construct wetlands (Nelson et al., 2001; Mitsch 1975; Mitsch, 2003). Pan et al. (2011), for instance, estimated the life cycle greenhouse gas (GHG) emissions for a CW and three centralized WTSs and concluded that the vertical subsurface flow $\mathrm{CW}$ was an effective option for GHG emissions mitigation in the wastewater sector. Similarly, Garfi et al. (2017) adopted a life cycle approach to compare the environmental impact of three alternatives for wastewater treatment and found that the CWs rather than non-nature-based ones were the most environmentally friendly options. De Feo and Ferrara (2017) pointed out that the CW system was the best environmental choice after 
considering three different LCA impact assessment methods and 81 comparative cases were considered. According to Chen et al. (2011), a CW is shown to be remarkably less carbon intensive than a typical centralized WTS when including the emissions induced by the inputs in the construction and operation stages. Shao et al. (2013) revealed that energy required for treating a unit of wastewater in a CW is much lower than treating it in a centralized WTS. Han et al. (2016) used process-based analysis to track the land use of a CW in China. Nevertheless, to our knowledge, few attempts on comparing the performances of CWs and centralized WTSs in terms of land use via a systems perspective have been made so far.

In this study, a new way of thinking is provided to understand the land use of a CW by taking full account of the inputs during the construction and operation stages. A CW is compared with a centralized WTS and a hybrid system to explore which alternative for wastewater treatment is superior in terms of land conservation. Scenario analysis has also been conducted to show the potential impacts by the wide deployment of CWs, with policy implications enunciated.

\section{Method and materials}

\subsection{Systems process analysis}

Process analysis is a widely used approach for calculating the resources use to produce all types of goods or services. It is appreciated for being capable of tracing the production chain of a product or technology in detail. The downside is that process analysis is time-consuming and may involve an infinite number of steps for the tracing, which have to be truncated after several steps. Generally, the tracing terminates after one or two steps and only the major inputs are taken into consideration. Thus, the process analysis is likely to be influenced by 
truncation errors and uncertainties associated with the subjective definitions of systems boundaries (Suh, 2009; Treloar, 1997).

Given this, Bullard et al. (1978) for the first time proposed the systems process analysis to calculate the resource use induced by atypical products or technologies, which combines the process analysis and resource intensity derived from systems input-output analysis. The systems input-output analysis was firstly proposed by Bullard and Herendeen (1973) and then further developed by Chen and his colleagues for calculating resource use (Chen et al., 2019; Guo et al., 2019) and environmental emissions (Chen and Chen, 2011; Mi et al., 2016; Zhang and Chen, 2010; Zhang et al., 2018). It is able to depict the interwoven relationships between economic sectors and has been used to help mitigate the truncation error involved in process analysis. The process analysis traces the production chain to a certain level at which the sub-inputs could be treated as typical products as categories in the input-output table. In this way, the aggregation errors that may be induced by the homogeneity assumption inherent to input-output tables could be avoided. The systems input-output analysis allows us to obtain the intensity database that details the resource use induced in the whole production chain to manufacture per unit of the sectoral output, which suitably mitigate the truncation errors associated with process analysis. By now, the systems process analysis has been widely extended to account for life cycle resource use and emissions induced by coal-fired power plants (Wu et al., 2018, 2019), renewable energy systems (Chen et al., 2011b, 2011c), building clusters (Chen et al., 2011; Li et al., 2019) and WTSs (Chen et al., 2011a; Shao et al., 2013).

It is worth noting that there are also some attempts trying to combine process analysis and 
intensities derived from environmental-extended input-output analysis. The environmental-extended input-output analysis assigns the resource use or emissions to final demand by means of the Leontief inverse matrix (Leontief, 1970). Therefore, the corresponding intensity is only defined for final products (namely products used as final demand) instead of intermediate products. For systems input-output analysis, it gives an objective evaluation of the resource use induced directly and indirectly to yield the sectoral output, regardless of whether the products are for intermediate or final use. For most production systems, the required items are intermediate inputs to support the producing processes. Therefore, using intensity database obtained from systems input-output database is justified.

\subsection{Case description}

Three WTSs are compared in this study, all of which are located in Beijing and have a designed lifetime of 20 years. The Longdao River Constructed Wetland (LRCW), which is located in the upper reaches of Longdao River and Wenyu River in Shunyi District of Beijing, was built in 2004 and put into use in the same year (Chen et al., 2008). It has a daily household wastewater treatment capacity of $200 \mathrm{~m}^{3}$ with an onsite land area of $900 \mathrm{~m}^{2}$ (adjacent to $21,700 \mathrm{~m}^{2}$ set aside for constructed wetland vegetation). The electricity consumption during the designed lifetime is $131,490 \mathrm{kWh}$ (Table 1). According to the original engineering data of the LRCW, the main inputs of the project include wetland plants, ten kinds of substrate, water conservancy and power auxiliary equipment.

A typical centralized WTS is represented by a cyclic activated sludge system (CASS) (Zhang, 2002) which is researched in this study in order to compare the land use of a CW. 
With coverage of $1,008 \mathrm{~m}^{2}$ onsite land area, daily treatment capacity of the CASS is $1,700 \mathrm{~m}^{3}$ and estimated electricity use is $396,807.6 \mathrm{kWh} /$ year. As an additional comparison, a hybrid wastewater treatment system (HS), occupying an onsite area of $15,215 \mathrm{~m}^{2}$, is included in this study. The original engineering data are available in Zhou (2008). It treats 5,600 $\mathrm{m}^{3}$ wastewater every day and has an electricity consumption of 964,260 kWh/year (Table 1).

The inflow and outflow samples in different seasons for the three systems were collected. Meanwhile, the raw wastewater being treated by any one of these three systems is greywater, in other words, wastewater generated from households or buildings not including toilet water. Details on sample collection and determination are presented in Zhou (2010). Removal efficiency (concentration-based) of five-day biological oxygen demand $\left(\mathrm{BOD}_{5}\right)$, chemical oxygen demand (COD), total suspended solid (TSS), and ammonia-nitrogen $\left(\mathrm{NH}_{3}-\mathrm{N}\right)$ for these three systems are displayed in Table 1 . The quality of effluent meets the requirements of Article 50 of the Law on Prevention and Control of Water Pollution (MEP, 2018).

Table 1

Technical parameters for the three wastewater treatment systems

\begin{tabular}{llll}
\hline Item & LRCW & HS & CASS \\
\hline Onsite land area $\left(\mathrm{m}^{2}\right)$ & 900 & 15,215 & 1,008 \\
Designed lifetime (year) & 20 & 20 & 20 \\
Daily treatment capacity of household wastewater (m ${ }^{3} /$ day) & 200 & 5600 & 1700 \\
Electricity use during the designed lifetime $(\mathrm{kWh} / \mathrm{year})$ & $6,574.5$ & $964,260.0$ & $396,807.6$ \\
Removal efficiency of $\mathrm{BOD}_{5}(\%)$ & $87.25 \pm 2.45$ & $85.94 \pm 2.07$ & $78.57 \pm 2.06$ \\
Removal efficiency of $\mathrm{COD}(\%)$ & $81.76 \pm 3.15$ & $83.53 \pm 2.81$ & $72.22 \pm 2.45$ \\
Removal efficiency of $\mathrm{TSS}_{(\%)}$ & $85.13 \pm 5.13$ & $84.17 \pm 2.69$ & $81.25 \pm 2.05$ \\
Removal efficiency of $\mathrm{NH}_{3}-\mathrm{N}(\%)$ & $77.34 \pm 5.54$ & $82.86 \pm 4.28$ & $83.33 \pm 2.73$ \\
\hline
\end{tabular}

Note: 22, 45, 17 and 18 repetitions of the sampling at different times for $\mathrm{BOD}_{5}, \mathrm{COD}$, TSS and $\mathrm{NH}_{3}-\mathrm{N}$ determination respectively. LRCW means Longdao River Constructed Wetland; HS means hybrid wastewater treatment system; and CASS means cyclic activated sludge system.

\subsection{Accounting steps}


The systems accounting for land use induced by three different kinds of wastewater treatment systemWTSs follows the steps below.

I. List the input items of the investigated system (complete inventory of materials, equipment and electric inputs of the construction and operation phases). Input items are quantified in monetary units. It is worth noting that the most important monetary input during the operation stage is electricity, while the material and other inputs are negligible, according to calculations by Shao et al., (2013).

II. Select an appropriate land use intensity database. The input-output table is updated periodically every few years. Economic classifications are quite flexible in different years. China's input-output table in 2002 contains a 42-sector classification; the table for 2007 divides the economy into 135 economic sectors. Therefore, it is critical to select a proper land use database that best fits the WTSs under investigation, since the land use intensity database reflected in input-output analysis varies greatly in different years. As the constructed wetland is built and put into use in 2004, the land use intensity database that corresponds to the 135-sector input-output table for China economy in 2007 is used. This is because of the fact that the supply chains of the constructed CW in Beijing may involve also other provinces and cities in China, due to the unprecedented expansion of urbanization. The country has grown into an integrated economic network and the cross-division of production chain has been formed, which has smeared out the industrial boundaries between the provinces and cities. Especially, Beijing has for long been a highly heterotrophic city relying on material, energy and service inputs from the rest of the country. The methodological details and calculating procedures are presented in Chen and Han (2015). 
III. Identify the corresponding economic sector for each input item. The relevant land use intensity is tracked for each input item.

IV. The monetary expenditure of each input is multiplied by its corresponding land use intensity. The land use for plant infrastructure is the summation of the land used for each input item, which is formulated as:

$$
T L U=\sum_{i} L U_{i}=\sum_{i}\left(L I_{i} \times M C_{i}\right),
$$

where, $T L U$ represents the total land use induced; $L U_{i}$ represents the embodied land use of the i-th input item; $L I_{i}$ represents the land use intensity of the i-th input item; $M C i$ represents the monetary cost of the i-th input item.

\section{Results and discussions}

\subsection{Inventory of the construction stage and land use induced}

For LRCW, vegetation is the biggest contributor. Then local organic substrate (composed of soil, fly ash, peat, bauxite, bentonite and so on) follows and electricity comes third (Table 2). Table 3 shows that a total amount of $2.05 \mathrm{E}+06 \mathrm{~m}^{2}$ land use is required by the construction stage of HS, with electricity accounting for more than $50 \%$. However, vegetation and local organic substrate are shown to occupy only $4.59 \%$ and $0.08 \%$ of the total (Table 3). Among all the input items of the CASS in the construction stage, the contribution by vegetation and local organic substrate is almost zero. Electricity as the biggest contributor, accounting for $67.89 \%$ of the total land use (Table 4 ).

Table 2

Inventory for the land use by the construction stage of the LRCW

\begin{tabular}{|c|c|c|c|c|c|c|}
\hline Item & & $\begin{array}{l}\text { Sector } \\
\text { code }\end{array}$ & Sector contents & $\begin{array}{l}\text { Embodied land use } \\
\text { intensity (m²/yuan) }\end{array}$ & $\begin{array}{l}\text { Embodied land } \\
\text { use }\left(\mathbf{m}^{2}\right)\end{array}$ & $\begin{array}{l}\text { Fraction } \\
(\%)\end{array}$ \\
\hline Geotextile & & 49 & Manufacture of plastic & $1.37 \mathrm{E}-01$ & $2.72 \mathrm{E}+03$ & 5.35 \\
\hline Local & organic & 5 & Services in support of agriculture & 2.77E-01 & $1.32 \mathrm{E}+04$ & 26.05 \\
\hline
\end{tabular}




\begin{tabular}{|c|c|c|c|c|c|}
\hline \multicolumn{6}{|l|}{ substrate } \\
\hline Mineral substrate & 10 & Mining and processing of nonmetal ores and other ores & $1.32 \mathrm{E}-01$ & $1.86 \mathrm{E}+03$ & 3.67 \\
\hline Other substrate & 52 & Manufacture of brick, stone and other building materials & $1.33 \mathrm{E}-01$ & $2.64 \mathrm{E}+03$ & 5.20 \\
\hline Vegetation & 1 & Farming & $7.60 \mathrm{E}-01$ & $2.17 \mathrm{E}+04$ & 42.63 \\
\hline Pump & 67 & Manufacture of pump, valve and similar machinery & $1.04 \mathrm{E}-01$ & $3.13 \mathrm{E}+02$ & 0.62 \\
\hline Pipe and valve & 49 & Manufacture of plastic & $1.37 \mathrm{E}-01$ & $5.59 \mathrm{E}+02$ & 1.10 \\
\hline Steel grille & 63 & Manufacture of metal products & $1.48 \mathrm{E}-01$ & $7.40 \mathrm{E}-01$ & 0.00 \\
\hline Bricks and cement & 50 & Manufacture of cement, lime and plaster & $1.23 \mathrm{E}-01$ & $5.43 \mathrm{E}+02$ & 1.07 \\
\hline Electricity & 92 & Production and supply of electric power and heat power & $8.57 \mathrm{E}-02$ & $7.15 \mathrm{E}+03$ & 14.07 \\
\hline $\begin{array}{l}\text { Total land } \\
\text { requirement }\end{array}$ & & & & $5.08 \mathrm{E}+04$ & 100.00 \\
\hline
\end{tabular}

As stated in existing studies, numerous works only focused on the operation of the wastewater treatment equipment (Zang et al., 2015). In addition to the operation stage, this study, however, gives full consideration to the construction stage by a comprehensive inclusion of the related inputs, including transportation pipeline, such as feeders, water collection system, and watershed diversion structures.

Table 3

Inventory for the land use by the construction stage of the HS

\begin{tabular}{|c|c|c|c|c|c|}
\hline Item & $\begin{array}{l}\text { Sector } \\
\text { code }\end{array}$ & Sector contents & $\begin{array}{l}\text { Embodied land use } \\
\text { intensity (m²/yuan) }\end{array}$ & $\begin{array}{l}\text { Embodied } \\
\text { land use }\left(\mathbf{m}^{2}\right)\end{array}$ & $\begin{array}{l}\text { Fraction } \\
(\%)\end{array}$ \\
\hline \multicolumn{6}{|l|}{ ABFT } \\
\hline $\begin{array}{l}\text { Aeration tank and } \\
\text { sedimentation tank }\end{array}$ & & & & & \\
\hline $\begin{array}{l}\text { Excavate, backfill, grave } \\
\text { cushion }\end{array}$ & 10 & Mining and processing of nonmetal ores and other ores & $1.32 \mathrm{E}-01$ & $2.09 \mathrm{E}+04$ & 1.01 \\
\hline Stone wall, soleplate and step & 95 & Construction & $1.73 \mathrm{E}-01$ & $5.76 \mathrm{E}+04$ & 2.80 \\
\hline Concrete & 51 & Manufacture of products of cement and plaster & $1.19 \mathrm{E}-01$ & $1.52 \mathrm{E}+03$ & 0.07 \\
\hline Reinforced bar & 59 & Rolling of steel & $9.35 \mathrm{E}-02$ & $3.89 \mathrm{E}+02$ & 0.02 \\
\hline Stainless steel railing & 63 & Manufacture of metal products & $1.48 \mathrm{E}-01$ & $1.05 \mathrm{E}+04$ & 0.51 \\
\hline Polyethylene board & 49 & Manufacture of plastic & $1.37 \mathrm{E}-01$ & $3.34 \mathrm{E}+03$ & 0.16 \\
\hline \multicolumn{6}{|l|}{ Abft tank } \\
\hline Excavate and backfill & 10 & Mining and processing of nonmetal ores and other ores & $1.32 \mathrm{E}-01$ & $3.68 \mathrm{E}+03$ & 0.18 \\
\hline Concrete & 51 & Manufacture of products of cement and plaster & $1.19 \mathrm{E}-01$ & $6.49 \mathrm{E}+04$ & 3.16 \\
\hline Reinforced bar & 59 & Rolling of steel & $9.35 \mathrm{E}-02$ & $2.17 \mathrm{E}+04$ & 1.06 \\
\hline Stainless steel railing, lander & 63 & Manufacture of metal products & $1.48 \mathrm{E}-01$ & $1.54 \mathrm{E}+04$ & 0.76 \\
\hline Equipment and material & & & & & \\
\hline
\end{tabular}




\begin{tabular}{|c|c|c|c|c|c|}
\hline $\begin{array}{l}\text { Aeration tank } \\
\text { sedimentation tank }\end{array}$ & & & & & \\
\hline Aeration machine & 72 & Manufacture of other special purpose machinery & $1.17 \mathrm{E}-01$ & $1.65 \mathrm{E}+04$ & 0.80 \\
\hline Steel griller & 63 & Manufacture of metal products & $1.48 \mathrm{E}-01$ & $1.10 \mathrm{E}+03$ & 0.05 \\
\hline Pump and valve & 67 & Manufacture of pump, valve and similar machinery & $1.04 \mathrm{E}-01$ & $6.71 \mathrm{E}+03$ & 0.33 \\
\hline Connecting hose & 49 & Manufacture of plastic & $1.37 \mathrm{E}-01$ & $5.20 \mathrm{E}+02$ & 0.03 \\
\hline Electromagnetic flowmeter & 88 & Manufacture of measuring instruments & $1.15 \mathrm{E}-01$ & $1.93 \mathrm{E}+03$ & 0.09 \\
\hline Embedded steel plate & 59 & Rolling of steel & $9.35 \mathrm{E}-02$ & $8.45 \mathrm{E}+01$ & 0.00 \\
\hline \multicolumn{6}{|l|}{ Blower room } \\
\hline Blower & 68 & Manufacture of other general purpose machinery & $1.10 \mathrm{E}-01$ & $1.01 \mathrm{E}+04$ & 0.49 \\
\hline $\begin{array}{l}\text { Electric control and power } \\
\text { system }\end{array}$ & 78 & $\begin{array}{l}\text { Manufacture of equipment for power transmission and } \\
\text { distribution and control }\end{array}$ & $1.13 \mathrm{E}-01$ & $1.88 \mathrm{E}+04$ & 0.91 \\
\hline \multicolumn{6}{|l|}{ Abft tank } \\
\hline Biological carrier & 43 & Manufacture of synthetic materials & $1.00 \mathrm{E}-01$ & $1.55 \mathrm{E}+05$ & 7.56 \\
\hline $\begin{array}{l}\text { Aeration hose, casing and } \\
\text { elbow }\end{array}$ & 49 & Manufacture of plastic & $1.37 \mathrm{E}-01$ & $9.70 \mathrm{E}+03$ & 0.47 \\
\hline $\begin{array}{l}\text { Intercept net, perforated sludge } \\
\text { discharge pipe, air duct, } \\
\text { stainless steel griller }\end{array}$ & 63 & Manufacture of metal products & $1.48 \mathrm{E}-01$ & $3.33 \mathrm{E}+04$ & 1.62 \\
\hline Butterfly valve & 67 & Manufacture of pump, valve and similar machinery & $1.04 \mathrm{E}-01$ & $7.67 \mathrm{E}+03$ & 0.37 \\
\hline Steel bracket & 59 & Rolling of steel & $9.35 \mathrm{E}-02$ & $4.95 \mathrm{E}+03$ & 0.24 \\
\hline Enzyme & 44 & Manufacture of special chemical products & $4.46 \mathrm{E}-01$ & $1.61 \mathrm{E}+05$ & 7.84 \\
\hline Embedded steel plate & 59 & Rolling of steel & $9.35 \mathrm{E}-02$ & $1.15 \mathrm{E}+03$ & 0.06 \\
\hline \multicolumn{6}{|l|}{ Tube settler sedimentation } \\
\hline Tube & 49 & Manufacture of plastic & $1.37 \mathrm{E}-01$ & $1.25 \mathrm{E}+04$ & 0.61 \\
\hline Steel bracket and plate & 59 & Rolling of steel & $9.35 \mathrm{E}-02$ & $7.29 \mathrm{E}+02$ & 0.04 \\
\hline Stainless steel overflow weir & 63 & Manufacture of metal products & $1.48 \mathrm{E}-01$ & $8.59 \mathrm{E}+02$ & 0.04 \\
\hline Rubber & 48 & Manufacture of rubber & $1.49 \mathrm{E}+00$ & $4.77 \mathrm{E}+02$ & 0.02 \\
\hline \multicolumn{6}{|l|}{ Pipes } \\
\hline \multicolumn{6}{|l|}{ Sump pump } \\
\hline ABFT valve well & 95 & Construction & $1.73 \mathrm{E}-01$ & $7.83 \mathrm{E}+02$ & 0.04 \\
\hline Elbow and tee joint & 49 & Manufacture of plastic & $1.37 \mathrm{E}-01$ & $7.09 \mathrm{E}+02$ & 0.03 \\
\hline \multicolumn{6}{|l|}{ Constructed wetland } \\
\hline \multicolumn{6}{|l|}{ Construction } \\
\hline Concrete & 51 & Manufacture of products of cement and plaster & $1.19 \mathrm{E}-01$ & $2.95 \mathrm{E}+04$ & 1.44 \\
\hline Non-woven fabrics & 28 & Manufacture of textile products & $2.72 \mathrm{E}-01$ & $7.23 \mathrm{E}+03$ & 0.35 \\
\hline Brick & 52 & $\begin{array}{l}\text { Manufacture of brick, stone and other building } \\
\text { materials }\end{array}$ & $1.33 \mathrm{E}-01$ & $2.61 \mathrm{E}+04$ & 1.27 \\
\hline $\begin{array}{l}\text { Polyethylene board, waterproof } \\
\text { carpet }\end{array}$ & 49 & Manufacture of plastic & $1.37 \mathrm{E}-01$ & $3.11 \mathrm{E}+04$ & 1.52 \\
\hline Excavate and backfill & 10 & Mining and processing of nonmetal ores and other ores & $1.32 \mathrm{E}-01$ & $1.10 \mathrm{E}+04$ & 0.54 \\
\hline \multicolumn{6}{|l|}{ Equipment and material } \\
\hline Pipe and accessory & 49 & Manufacture of plastic & $1.37 \mathrm{E}-01$ & $5.53 \mathrm{E}+03$ & 0.27 \\
\hline Valve & 67 & Manufacture of pump, valve and similar machinery & $1.04 \mathrm{E}-01$ & $2.32 \mathrm{E}+03$ & 0.11 \\
\hline
\end{tabular}




\begin{tabular}{|c|c|c|c|c|c|}
\hline \multicolumn{6}{|l|}{ Substrate } \\
\hline Mineral substrate & 10 & Mining and processing of nonmetal ores and other ores & 1.32E-01 & $1.48 \mathrm{E}+05$ & 7.19 \\
\hline Local organic substrate & 1 & Farming & $7.60 \mathrm{E}-01$ & $1.73 \mathrm{E}+03$ & 0.08 \\
\hline \multicolumn{6}{|l|}{ Vegetation } \\
\hline $\begin{array}{l}\text { Acorus calamus, reed, cyperus } \\
\text { rotundus }\end{array}$ & 1 & Farming & 7.60E-01 & $9.43 \mathrm{E}+04$ & 4.59 \\
\hline \multicolumn{6}{|l|}{ Pipes } \\
\hline Valve well & 95 & Construction & $1.73 \mathrm{E}-01$ & $5.47 \mathrm{E}+03$ & 0.27 \\
\hline Elbow and tee joint & 49 & Manufacture of plastic & $1.37 \mathrm{E}-01$ & $1.11 \mathrm{E}+03$ & 0.05 \\
\hline Electricity & 92 & Production and supply of electric power and heat power & 8.57E-02 & $1.05 \mathrm{E}+06$ & 50.93 \\
\hline Total land requirement & & & & $2.05 \mathrm{E}+06$ & 100.00 \\
\hline
\end{tabular}

For LRCW, the contribution of vegetation and local substrates to the total land use by the construction stage is significantly higher than that of the other two systems. While for CASS, the contribution of vegetation and local substrates to the total land use by the construction stage is marginally negligible. As witnessed, all the substrates used in the construction stage of this CW are mainly excavated nearby, and some are even from immediate local sources, such as the soil and the sand. Moreover, a CW requires minimal onsite civil engineering work. In comparison, CASS requires a tremendous number of expensive and land-intensive inputs from domestic heavy industry sectors, resulting the high amount of land use induced in the construction stages. Therefore, compared with LRCW, CASS indirectly induces a much larger amount of land use in the construction stage, which is generally neglected in existing studies and policy packages. This might also well support the argument that CW system for wastewater treatment as one of the most important applications of ecological engineering, can provide the optimal wastewater treatment scheme with low capital cost and resource consumption, and finally realize the beneficial saving of natural resources (Zhang et al., 2009).

Table 4

Inventory for the land use by the construction stage of the CASS 


\begin{tabular}{|c|c|c|c|c|c|}
\hline Item & $\begin{array}{l}\text { Sector } \\
\text { code }\end{array}$ & Sector contents & $\begin{array}{l}\text { Embodied land use } \\
\left.\text { intensity ( } \mathrm{m}^{2} / \mathrm{yuan}\right)\end{array}$ & $\begin{array}{l}\text { Embodied land } \\
\text { use }\left(\mathbf{m}^{2}\right)\end{array}$ & $\begin{array}{l}\text { Fraction } \\
(\%)\end{array}$ \\
\hline Pump & 67 & Manufacture of pump, valve and similar machinery & $1.04 \mathrm{E}-01$ & $3.74 \mathrm{E}+03$ & 0.59 \\
\hline Steel grille & 63 & Manufacture of metal products & $1.48 \mathrm{E}-01$ & $1.48 \mathrm{E}+03$ & 0.23 \\
\hline Equipment & 72 & Manufacture of other special purpose machinery & $1.17 \mathrm{E}-01$ & $4.53 \mathrm{E}+04$ & 7.13 \\
\hline Electric control & 78 & $\begin{array}{l}\text { Manufacture of equipment for power transmission and } \\
\text { distribution and control }\end{array}$ & $1.13 \mathrm{E}-01$ & $1.13 \mathrm{E}+04$ & 1.78 \\
\hline Pipe and accessory & 49 & Manufacture of plastic & $1.37 \mathrm{E}-01$ & $1.37 \mathrm{E}+04$ & 2.16 \\
\hline $\begin{array}{l}\text { Basin, room and } \\
\text { shaft }\end{array}$ & 95 & Construction & $1.73 \mathrm{E}-01$ & $1.28 \mathrm{E}+05$ & 20.22 \\
\hline Electricity & 92 & Production and supply of electric power and heat power & 8.57E-02 & $4.31 \mathrm{E}+05$ & 67.89 \\
\hline $\begin{array}{l}\text { Total land } \\
\text { requirement }\end{array}$ & & & & $6.35 \mathrm{E}+05$ & 100.00 \\
\hline
\end{tabular}

3.2. Total land use induced by construction and operation stages

The component profiles of land use induced by the construction and operation stage of the three WTSs are shown in Figure 1. As can be observed, for all these three types of WTSs, the land use induced by the construction stage is larger than that of the operation stage. This is primarily due to the fact that the monetary cost for the material and machinery inputs in the construction stage is quite high. Meanwhile, the inputs required in the operation stage (mainly electric power) are relatively much less land-intensive compared with various land-intensive inputs in the construction stage, mainly the materials and equipment from the heavy manufacturing industries. The results obtained in this paper differ from other former research projects focusing on energy use, which revealed that the energy use induced by the operation stage is much greater than that of the construction stage for WTSs (Ko et al., 2004; Lundin et al., 2000; Shao et al., 2013; Zhang et al., 2010). This can be attributed to the fact that electricity as the most important input in the operation stage of WTS is quite energy-intensive but not land-intensive as compared to the inputs in the construction stage. As shown in this study, electricity, which belongs to Sector 92 (Production and supply of electric power and 
heat power) in the input-output table for the economy, requires a tremendous amount of energy-intensive inputs (such as fossil fuel inputs, heavy machinery in terms of boilers, turbines and generators, and services in terms of transportation and construction) from other sectors to yield the electricity output.

Furthermore, the operation phase for CASS takes up a greater share than that for LRCW, while the proportion for construction phase is smaller than that of CW, as illustrated in Fig. 1. This is mainly due to the vast electricity required for lifting, transporting, mixing, stirring, and dehydrating during the operation stage of centralized wastewater treatment plants, compared to CWs. Meanwhile, the capital investment of vegetation and local substrates in the construction stage of LRCW is $12.61 \%$ and $21.11 \%$ of the total capital investment, respectively; in contrast, this share for HS has decreased, and this share for CASS is zero.

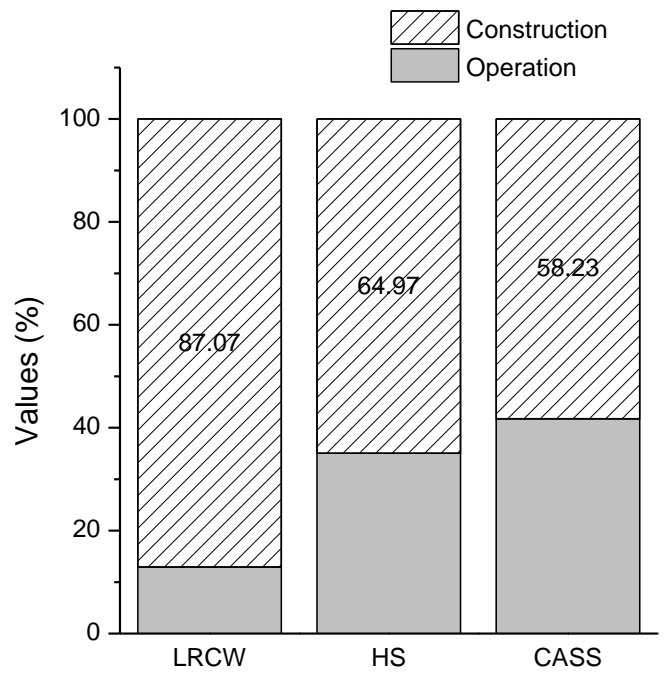

Fig. 1. The proportion of embodied land in the construction and operation stages of different wastewater treatment systems

\subsection{Comparison with direct land occupation}

In this study, it is calculated that LRCW, HS and CASS respectively induce a total amount 
of $5.83 \mathrm{E}+04,3.16 \mathrm{E}+06$ and $1.09 \mathrm{E}+06 \mathrm{~m}^{2}$ land use during their construction and operation stages, with direct land occupation of $1.80 \mathrm{E}+04,3.04 \mathrm{E}+05$ and $2.02 \mathrm{E}+04 \mathrm{~m}^{2}$ during the lifetime. The indirect land use, defined as the land use induced, is revealed as in magnitude 3.24, 4.33 and 53.95 times as large as direct land occupation for LRCW, HS and CASS, respectively (Fig. 2). It is proved that indirect land use by the production of required energy, materials and machinery inputs should be taken into account to give an overall reflection of the life cycle land use of WTSs. This finding is consistent with extensive studies on indirect land use on different scales. For instance, Yu et al. (2013) pointed out that land use attributed to "unusual" sectors, including machinery, construction and services, accounts for massive land use. Meanwhile, according to Wu et al. (2018b), indirect arable land use induced by internationally traded products is in magnitude up to $40 \%$ of the total arable land exploited. As seen, the results obtained in this study are in good accordance with previous studies and have demonstrated the remarkable land use induced by plant infrastructure and operation that has been traditionally ignored.

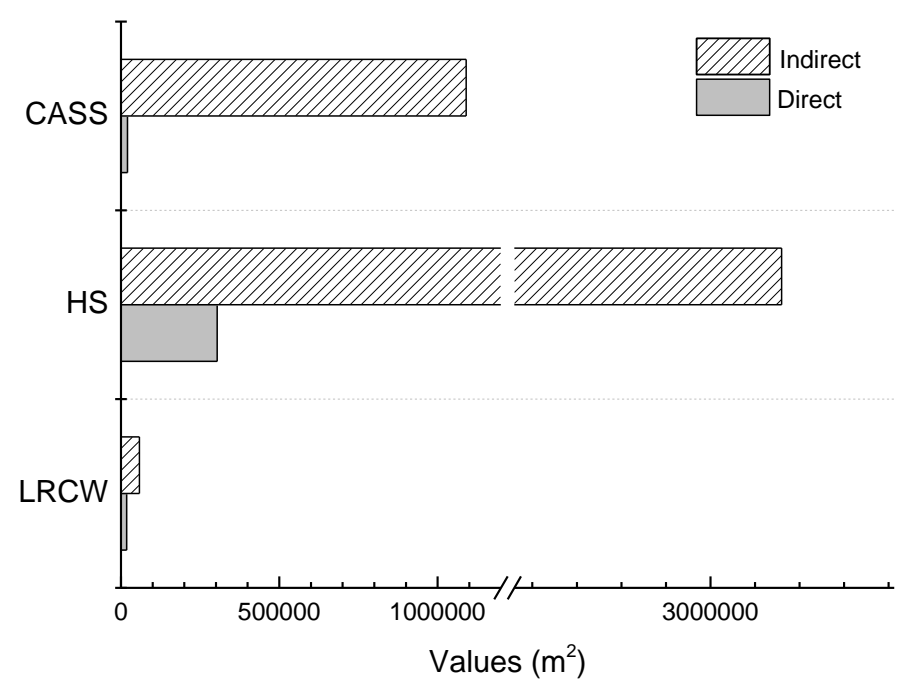

Fig. 2. Direct land occupation and indirect land use of different wastewater treatment systems 
during the twenty-year lifetime

\subsection{Induced land use by type}

Among the different land types, the proportion of agricultural land is much higher than that of non-agricultural land (Fig. 3a, 4a and 5a). Generally speaking, the agriculture land resources enter into the economy through the agriculture sector and support the production of agriculture products. Within the economy depicted by input-output table, the agricultural products will come into the second and tertiary industries as intermediate inputs, which means that the use of agricultural land is supportive for not only the production of agricultural products but also all other products along the value chain due to the interconnected linkages between economic sectors. Therefore, though the products by second or tertiary industry may not directly require agriculture land, they may indirectly induce a large amount of land use in upstream processes. This could provide a new perspective for future policy decisions by reminding us to fully consider the agricultural land use induced by each project. The results suggest that it is essential to take full account of the interlinkage between different sectors and improve the existing policy framework in order to relieve the increasing pressure of wastewater treatment on different kinds of land use.

Another point that can be concluded from Figure $3 b, 4 b$ and $5 b$ is that the non-agriculture (including transportation, residential, water conservancy facility and industrial land), especially industrial land use induced by LRCW is much less than those by HS and CASS. For HS and CASS, massive industrial inputs, including associated building products, electricity and machinery, are required in the construction activities, which induce a great deal of industrial land use in the supply chains. 
(a)

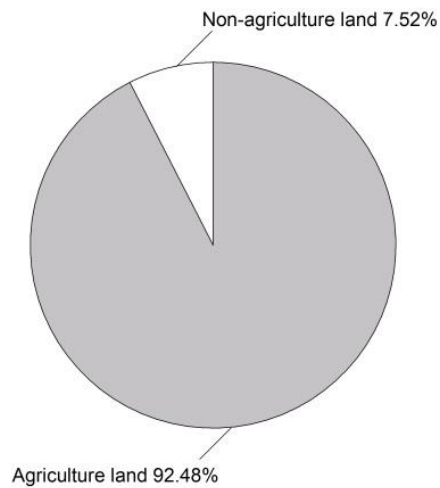

(b)

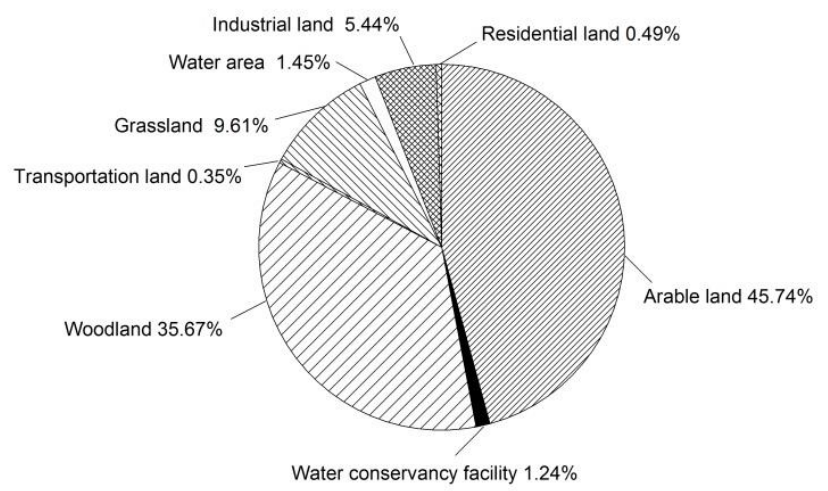

Fig. 3. (a) Proportion of agriculture and non-agriculture land; (b) Land use by type for LRCW

(a)

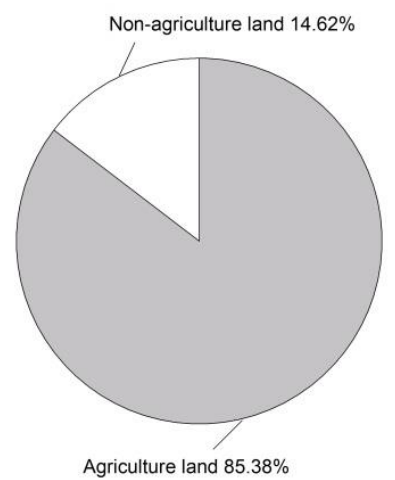

(b)

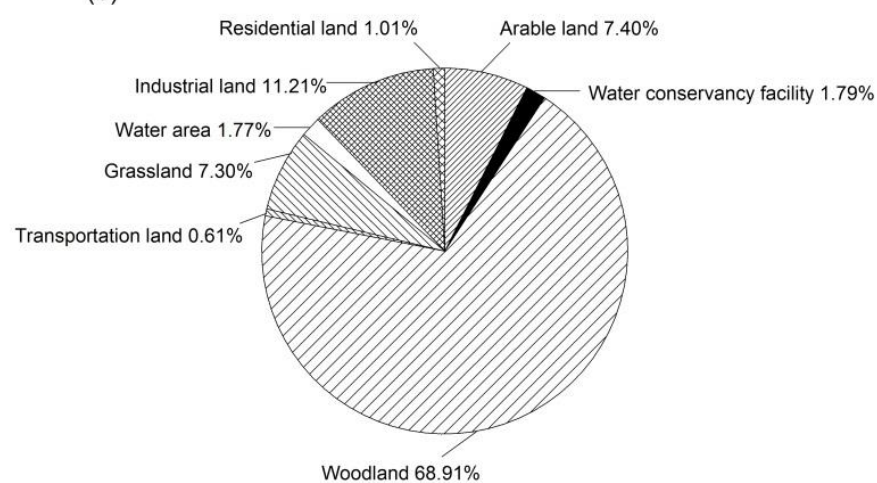

Fig. 4. (a) Proportions of agriculture and non-agriculture land; (b) Land use by type for HS

(a)

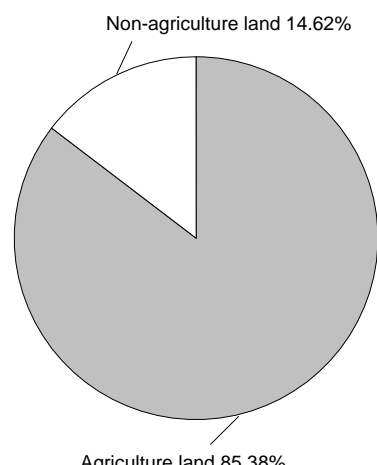

(b)

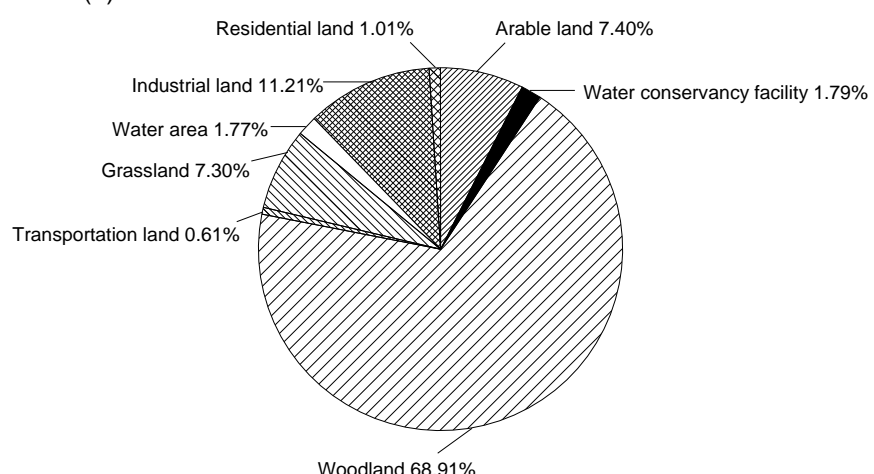

Fig. 5. (a) Proportions of agriculture and non-agriculture land; (b) Land use by type for CASS

3.5. Land use required for treating per $\mathrm{m}^{3}$ wastewater and removing per $\mathrm{kg} \mathrm{BOD}$, $\mathrm{COD}$, TSS and $\mathrm{NH}_{3}-\mathrm{N}$ 
Among the three kinds of WTSs, a surprising finding is that the land use required for treating per $\mathrm{m}^{3}$ wastewater of this $\mathrm{CW}$ is significantly smaller than that of the centralized and hybrid WTS, as seen in Fig. 6a. Meanwhile, the land use required for removing per kg BOD, COD, TSS, and $\mathrm{NH}_{3}-\mathrm{N}$ of the LRCW is $60.95 \%, 66.97 \%, 72.97 \%$ and $64.21 \%$ of that of the CASS, respectively (Fig. 6b). By removing per $\mathrm{kg}$ of $\mathrm{BOD}_{5}, \mathrm{COD}$, TSS, and $\mathrm{NH}_{3}-\mathrm{N}, \mathrm{CW}$ saves $33.98 \%, 27.46 \%, 20.96 \%$ and $30.45 \%$ of induced agricultural land and $68.66 \%, 65.56 \%$, $62.48 \%, 66.98 \%$ of induced non-agricultural land than the centralized WTS. According to the results, it is found that the ecological engineering of the CWs is remarkably less land-use-intensive than the centralized WTS.

This is contrary to our previous belief that centralized WTSs are more land-conservative than CWs. From an onsite perspective, a CW uses more onsite land area than a centralized WTS and is more suited to be deployed in suburb areas. From a systems perspective, however, the indirect land use is in magnitude much higher than the direct land occupation and a $\mathrm{CW}$ is revealed to have an obvious advantage over a traditional WTS in terms of land use. CWs are designed in a way similar to natural wetlands and make use of physical, chemical and biological synergies of soil, plants and microorganisms to deal with the contaminants in wastewater, which requires a small number of material and other inputs in the construction and operation stages. In contrast, centralized WTSs require a lot of external inputs, which could induce much more land use in the upstream processes compared to CWs. Just as previously noted, once the land is exploited for economic uses, the land use keeps circulated in the economic network via the supply chain and support the production of all commodities in the economy. Therefore, though many industrial products require not too much land use in 
the production processes, the land use induced to support the input items may be significant. Even for the service inputs that direct require little land use, they may also be land intensive. The large amount of land use induced by the massive input items of centralized WTS demonstrates that it may not be land-conservative as generally believed. Meanwhile, as described by Millennium Ecosystem Assessment (MEA), people could directly obtain benefits from ecosystems (MEA, 2005). CWs as planned and managed semi-natural systems are used in wastewater treatment to capture the value from ecosystem by effectively mimicking processes normally performed by conventional, gray infrastructure technologies, which is much more ecological friendly and land-conservative than the anthropogenic production system.
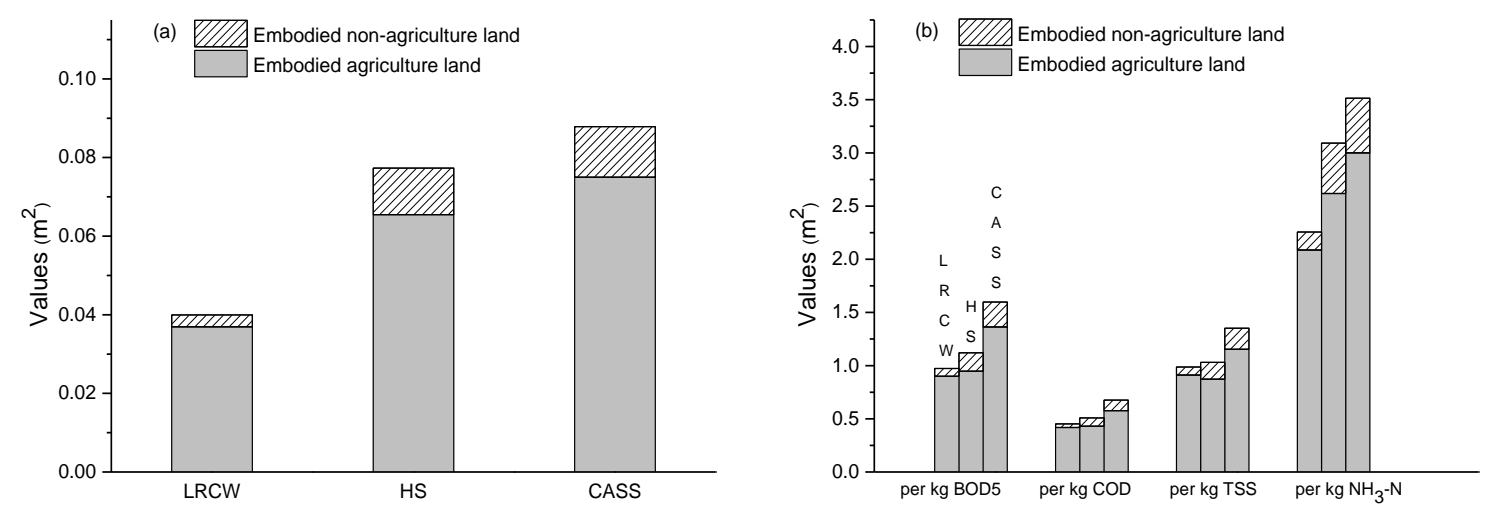

Fig. 6. Land use required for treating per $\mathrm{m}^{3}$ wastewater and removing per $\mathrm{kg} \mathrm{BOD}_{5}, \mathrm{COD}$, TSS and $\mathrm{NH}_{3}-\mathrm{N}$

\subsection{Scenario analysis and implications}

The total amount of urban wastewater discharged and treated in China has kept increasing year by year since 2004 (Fig. 7). The capacity and efficiency for wastewater treatment are improving which may be due to the continuous enhancement of public awareness of 
environmental protection and improvement of special wastewater treatment technology as well as the associated legal system. However, China is still faced with the concern of the continuously growing wastewater discharge along with rapid urbanization.

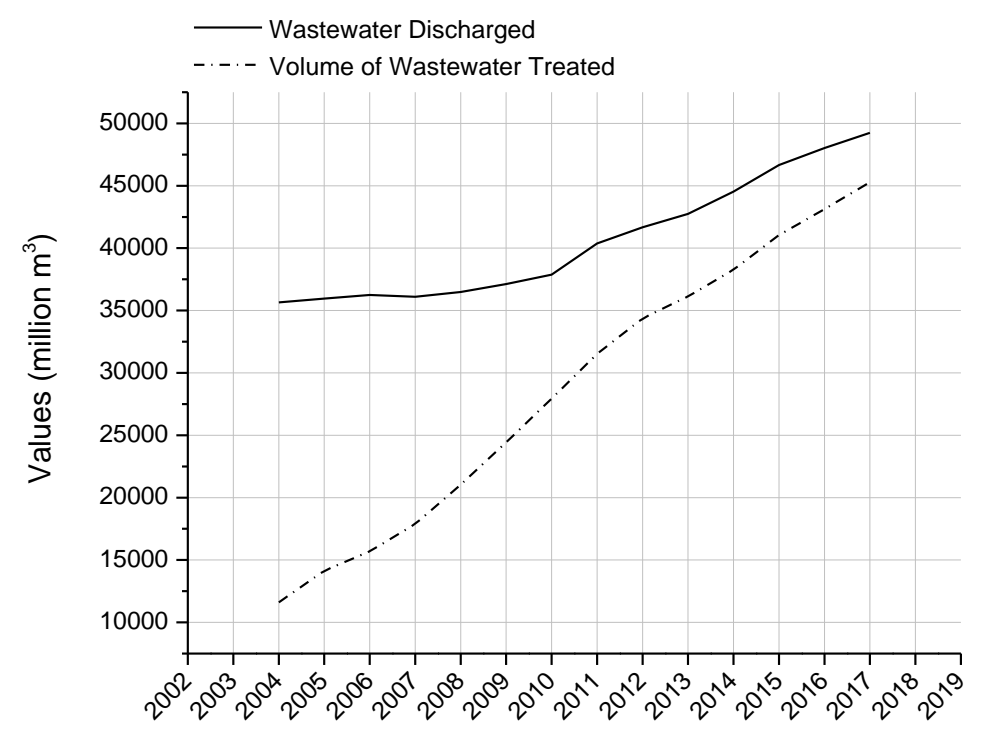

Fig. 7. The volume of urban wastewater discharged and treated 2004-2017 in China

By the end of December 2017, a total number of 2,209 urban centralized wastewater treatment plants (excluding township and industries wastewater treatment plants) had been built in cities in China, with a wastewater treatment capacity of 157.43 million $\mathrm{m}^{3}$ per day, according to China Environmental Statistics Yearbook (CSP, 2018). The amounts of wastewater discharged and treated in Chinese cities in the year of 2017 are both presented in Figure 8. 


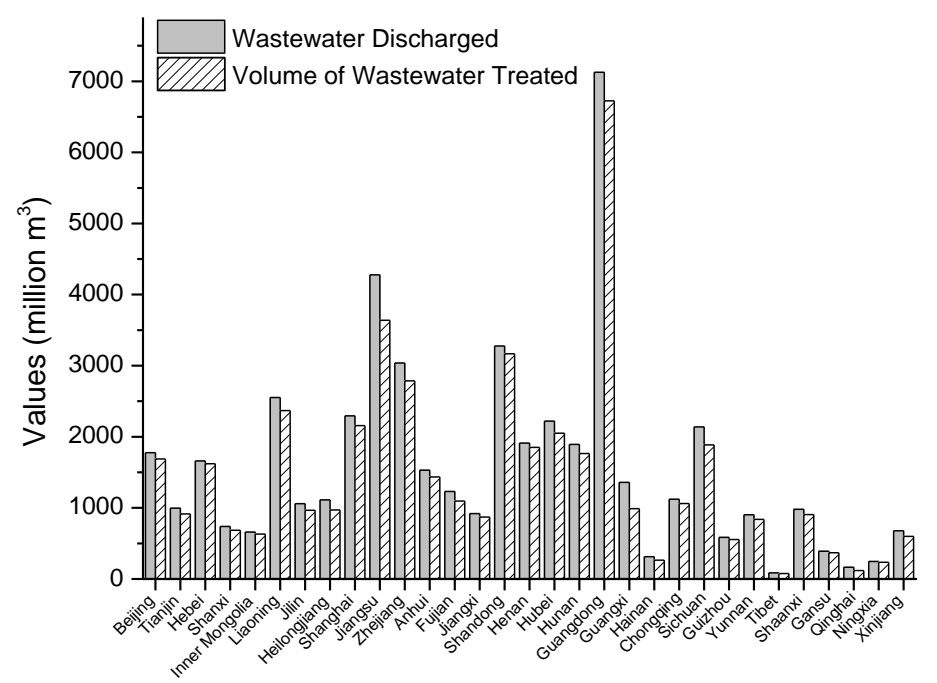

Fig. 8. The amount of wastewater discharged and treated in Chinese cities in 2017

According to the above calculations, the CW utilizes $0.05 \mathrm{~m}^{2}$ less than the centralized WTS when one $\mathrm{m}^{3}$ wastewater is treated. Therefore, it can be preliminarily estimated that if all urban centralized WTSs in 2017 are replaced by CWs, an enormous amount of land use induced (about 2.17 billion $\mathrm{m}^{2}$ ) could be reduced.

If the Chinese urban WTSs are replaced by CWs, the amount of land saved by each province and land saved per capita by each province in 2017 are illustrated in Fig. 9. Meanwhile, it is necessary to note that since the physical boundaries between the provinces and cities have been gradually smeared out as mentioned previously and the cross-division of production chain has been formed, a system that physically situates in a city/provinces may need energy, material and equipment inputs from the rest of the country. Therefore, land use intensity for China economy instead of that for regional economy was used to give preliminary estimation. Such preliminary scenario analysis could provide a basis for making of provincial wastewater treatment policies. 


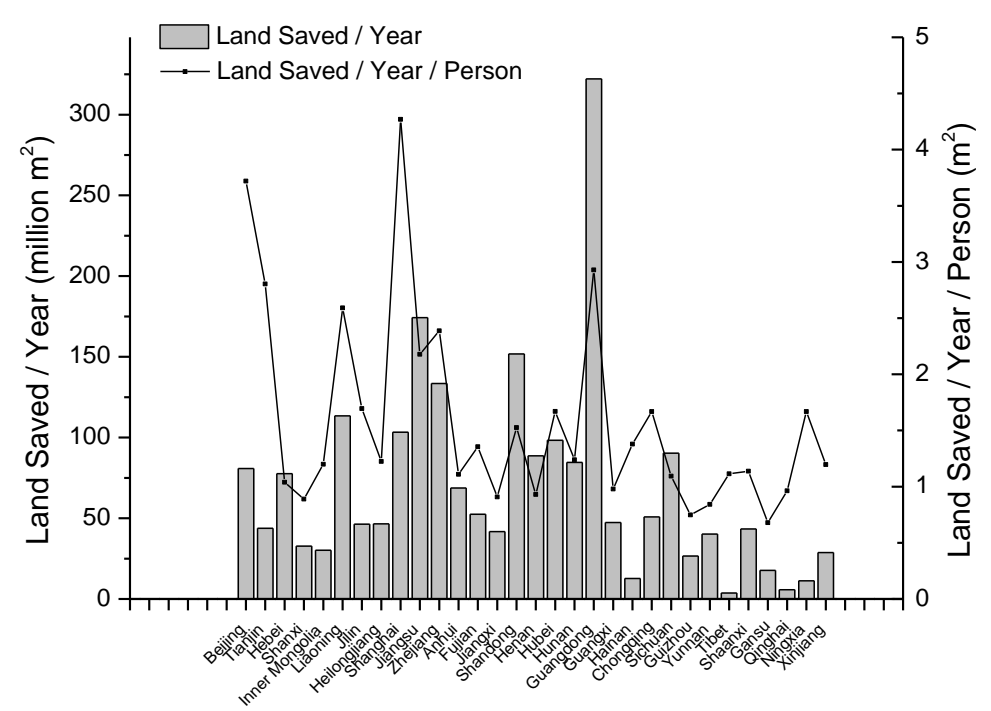

Fig. 9. The total and per-capita land use saved per year

Previous studies have shown that $\mathrm{CW}$ wastewater treatment plants have less impact on the environment than centralized wastewater treatment plants (Austin and Nivala, 2009). It has also been reported that $\mathrm{CW}$ wastewater treatment plants are less energy-intensive (Shao et al., 2013) and carbon-intensive (Chen et al., 2011a) than the centralized ones. Furthermore, it is generally accepted that CWs have many ecological benefits over the centralized wastewater treatment plants, such as biodiversity maintaining and carbon sequestration (Shaharuddin et al., 2013). In addition to the benefits reported above, CWs are delivering cultural services in the form of educational tours.

What has been discussed above has supported the argument that a $\mathrm{CW}$ is more favorable when compared with a centralized WTS. Given the advantages of CWs in treating wastewater, Chinese government has carried out a series of policy incentives for the development of CWs. In 2000, the Chinese government promulgated the technical policy on Urban Wastewater Treatment and Pollution Prevention, which emphasizes that the prevention and control of secondary pollution should be given due attention in urban wastewater treatment. It also 
advocates the use of reclaimed water in agricultural irrigation, green irrigation, ecological restoration and industrial cooling. In order to standardize the construction, operation, maintenance and management of $\mathrm{CW}$ wastewater treatment projects in China, the set of standards, Technical Specification of Constructed Wetlands for Wastewater Treatment Engineering, has been enacted and implemented since 2011. The standing committee of the National People's Congress of the People's Republic of China further amended the law on Prevention and Control of Water Pollution in 2018, with special emphasis on building CWs in line with local conditions to improve the carrying capacity of environmental resources in river basins.

A similarity inherent in these policy packages is that although ecological advantages of CWs are acknowledged, while much anxiety has been given to the hypothetical threat that expansion of CWs deployment may increase great pressures on the availability of land resources. Therefore, the promotion of CWs in urban area is greatly hindered due to the large onsite area required. This study revealed that, despite the superficial observation that centralized WTSs require less onsite area than CWs, the wide deployment of WTSs in cities may induce a much greater quantity of land use in upstream processes, which may cast more pressure on the available land resources. In context of the limited availability of land resources, the system accounting revealed that substantial land use could be reduced if centralized WTSs are replaced by CWs. This provides a systems view for the refinement of the existing land planning and wastewater treatment policies.

\section{Concluding remarks}

A typical CW in Beijing as an ecological project to treat wastewater is studied, supported 
by a comprehensive inventory of inputs and the land use intensity database. Parallel calculations are carried out for two systems for comparison: one is a hybrid system of centralized WTS and CW, and another one is a typical centralized WTS. According to the results of assessment, indirect land use is much larger than onsite land occupation for these three WTSs. Therefore, the importance of indirect land use cannot be ignored in the overall land assessment. Moreover, land use in the construction phase, which is usually overlooked, exceeds that in the operational phase for these three WTSs. The key finding of this study is that total land use required for treating per unit wastewater of CWs is smaller than that of centralized WTSs. Thus, CWs are more likely to help achieve the goal of land conservation than centralized WTSs, which goes beyond the conventional belief that CWs are land-intensive and not suitable for promotion in urbanized areas. The outcome of this study could provide a benchmark for future studies and a reference for policy enactment.

\section{Acknowledgements}

This research was funded by the National Natural Science Foundation of China (11802032), the Fundamental Research Funds for the Central Universities (Nos. 2019ZY34 and 2019BLRD05), the Beijing Forestry University Outstanding Young Talent Cultivation Project (2019JQ03002), and the Young Talent Supporting Engineering of China Association for Science and Technology (2019 - 2021QNRC001).

\section{References}

Amaral, R., Ferreira, F., Galvao, A., Matos, J.S., 2013. Constructed wetlands for combined sewer overflow treatment in a Mediterranean country, Portugal. Water Science and Technology 67(12), 2739-2745.

Austin, D., Nivala, J., 2009. Energy requirements for nitrification and biological nitrogen removal in engineered wetlands. Ecological Engineering 35(2), 184-192.

Brown, D., 1994. Constructed Wetlands in the USA. U.S. Environmental Protection Agency, Washington, D.C., EPA/600/J-95/216.

Bullard, C.W., Penner, P.S., Pilati, D.A., 1978. Net energy analysis : Handbook for combining process and input-output analysis. Resources and Energy 1(3), 267-313.

Bullard III, C., Herendeen, R.A., 1973. Energy use in the commercial and industrial sectors of the US economy, 1963. NASA STI/Recon Technical Report N 75, 16104. 
Chen, G.Q., Chen, H., Chen, Z., Zhang, B., Shao, L., Guo, S., Zhou, S., Jiang, M., 2011. Low-carbon building assessment and multi-scale input-output analysis. Communications in Nonlinear Science and Numerical Simulation 16(1), 583-595.

Chen, G.Q., Han, M.Y., 2015. Virtual land use change in China 2002-2010: internal transition and trade imbalance. Land Use Policy 47, 55-65.

Chen, G.Q., Wu, X., Guo, J., Meng, J., Li, C., 2019. Global overview for energy use of the world economy: Household-consumption-based accounting based on the world input-output database (WIOD). Energy Economics 81, 835-847.

Chen, G.Q., Shao, L., Chen, Z.M., Li, Z., Zhang, B., Chen, H., Wu, Z., 2011a. Low-carbon assessment for ecological wastewater treatment by a constructed wetland in Beijing. Ecological Engineering 37(4), 622-628.

Chen, G.Q., Yang, Q., Zhao, Y.H., 2011b. Renewability of wind power in China: A case study of nonrenewable energy cost and greenhouse gas emission by a plant in Guangxi. Renewable \& Sustainable Energy Reviews 15(5), 2322-2329.

Chen, G.Q., Yang, Q., Zhao, Y.H., Wang, Z.F., 2011c. Nonrenewable energy cost and greenhouse gas emissions of a $1.5 \mathrm{MW}$ solar power tower plant in China. Renewable \& Sustainable Energy Reviews 15(4), 1961-1967.

Chen, Z.M., Chen, G., 2011. Embodied carbon dioxide emission at supra-national scale: a coalition analysis for G7, BRIC, and the rest of the world. Energy Policy 39(5), 2899-2909.

Chen, Z.M., Chen, B., Zhou, J.B., Li, Z., Zhou, Y., Xi, X.R., Lin, C., Chen, G.Q., 2008. A vertical subsurface-flow constructed wetland in Beijing. Communications in Nonlinear Science \& Numerical Simulation 13(9), 1986-1997.

CSP, 2018. China Environmental Statistics Yearbook. China Statistics Press, Beijing.

De Feo, G., Ferrara, C., 2017. A procedure for evaluating the most environmentally sound alternative between two on-site small-scale wastewater treatment systems. Journal of Cleaner Production 164, 124-136.

Eifert, W., 1999. Enhanced subsurface flow constructed wetland. Google Patents.

Garfí, M., Flores, L. and Ferrer, I., 2017. Life cycle assessment of wastewater treatment systems for small communities: activated sludge, constructed wetlands and high rate algal ponds. Journal of Cleaner Production 161, 211-219.

Guo, S., Jiang, L., Chen, G.Q., 2019. Embodied pasture land use change in China 2000-2015: From the perspective of globalization. Land Use Policy 82, 476-485.

Han M.Y., 2016. Embodied land use: multi-scale systems accounting and its enguneering applications. Doctoral dissertation, University of Peking University (in Chinese).

Kivaisi, A.K., 2001. The potential for constructed wetlands for wastewater treatment and reuse in developing countries: a review. Ecological Engineering 16(4), 545-560.

Ko, J.Y., Day, J.W., Lane, R.R., Day, J.N., 2004. A comparative evaluation of money-based and energy-based cost-benefit analyses of tertiary municipal wastewater treatment using forested wetlands vs. sand filtration in Louisiana. Ecological Economics 49(3), 331-347.

Lave, L.B., Cobas-Flores, E., Hendrickson, C.T., McMichael, F.C., 1995. Using input-output analysis to estimate economy-wide discharges. Environmental Science \& Technology 29, 420A-426A.

Leontief, W., 1970. Environmental repercussions and the economic structure: an input-output approach. The Review of Economics and Statistics 52(3), 262-271.

Li, X.Y., Ding, A.Z., Zheng, L., Xing, L., Dong, Y.L., Tan, Z., Liu, B.Y. and Zhang, L., 2018. Application of 
Constructed Wetlands for Water Pollution Treatment in China During 1990-2015. Environ Eng 26(4), 11-17.

Li, Y.L., Han, M.Y., Liu, S., Chen, G.Q., 2019. Energy consumption and greenhouse gas emissions by buildings: A multi-scale perspective. Building and Environment 151, 240-250.

Liu X., 2017. Treatment Status and Prospect of Rural Domestic Sewage in China. Journal of Anhui Agriculture Science. 45(12): 58-60 (in Chinese).

Lu, S., Zhang, X., Wang, J., Pei, L., 2016. Impacts of different media on constructed wetlands for rural household sewage treatment. Journal of Cleaner Production 127, 325-330.

Lundin, M., Bengtsson, M., Molander, S., 2000. Life Cycle Assessment of Wastewater Systems: Influence of System Boundaries and Scale on Calculated Environmental Loads. Environmental Science \& Technology 34(1), 180-186.

Masi, F., Rizzo, A., Bresciani, R. and Conte, G., 2017. Constructed wetlands for combined sewer overflow treatment: ecosystem services at Gorla Maggiore, Italy. Ecological Engineering 98, 427-438.

MEA (Millennium Ecosystem Assessment), 2005. Ecosystems and their services. In Ecosystems and Human well-being: A framework for assessment. Washington, DC: Island Press.

MEP (Ministry of Environmental Protection of China), 2018. Law on Prevention and Control of Water Pollution art. 50 (P.R.C.).

Merlin, G., Pajean, J.L., Lissolo, T., 2002. Performances of constructed wetlands for municipal wastewater treatment in rural mountainous area. Hydrobiologia 469(1-3), 87-98.

Mi, Z.F., Zhang, Y., Guan, D., Shan, Y., Liu, Z., Cong, R., Yuan, X.C., Wei, Y.M., 2016. Consumption-based emission accounting for Chinese cities. Applied Energy 184, 1073-1081.

Mitsch, W.J., 1975. Systems analysis of nutrient disposal in cypress wetlands and lake ecosystems in Florida. Doctoral dissertation, University of Florida.

Mitsch, W.J., 2003. Ecology, ecological engineering, and the Odum brothers. Ecological Engineering 20, 331-338.

Nelson, M., Odum, H.T., Brown, M.T. and Alling, A., 2001. "Living off the land": resource efficiency of wetland wastewater treatment. Advances in Space Research 27(9), 1547-1556.

Otterpohl, R., Braun, U., Oldenburg, M., 2004. Innovative technologies for decentralised water-, wastewater and biowaste management in urban and peri-urban areas. Water science and technology 48(11-12), 23-32.

Pálfy, T.G., Gourdon, R., Meyer, D., Troesch, S., Olivier, L. and Molle, P., 2017. Filling hydraulics and nitrogen dynamics in constructed wetlands treating combined sewer overflows. Ecological Engineering 101, 137-144.

Pan, T., Zhu, X.-D., Ye, Y.-P., 2011. Estimate of life-cycle greenhouse gas emissions from a vertical subsurface flow constructed wetland and conventional wastewater treatment plants: A case study in China. Ecological Engineering 37(2), 248-254.

Parkinson, J., Tayler, K., 2003. Decentralized wastewater management in peri-urban areas in low-income countries. Environment and Urbanization 15(1), 75-90.

Richardson, C.J., 1994. Ecological functions and human values in wetlands: A framework for assessing forestry impacts. Wetlands 14(1), 1-9.

Seidel, K., 1955. Die Flechtbinse Scirpus lacustris L.

Shaharuddin, S., Zakaria, N.A., Ghani, A.A., Chang, C.K., 2013. Performance Evaluation of Constructed Wetland in Malaysia for Water Security Enhancement, lahr World Congress.

Shao, L., Wu, Z., Zeng, L., Chen, Z.M., Zhou, Y., Chen, G.Q., 2013. Embodied energy assessment for 
ecological wastewater treatment by a constructed wetland. Ecological Modelling 37(4), 622-628.

Suh, S., 2009. Handbook of Input-Output Economics in Industrial Ecology.

Tao, W., Bays, J.S., Meyer, D., Smardon, R.C., Levy, Z.F., 2014. Constructed wetlands for treatment of combined sewer overflow in the US: A review of design challenges and application status. Water 6(11), 3362-3385.

Treloar, G.J., 1997. Extracting Embodied Energy Paths from Input-Output Tables: Towards an InputOutput-based Hybrid Energy Analysis Method. Economic Systems Research 9(4), 375-391.

Vymazal, J., 2005. Horizontal sub-surface flow and hybrid constructed wetlands systems for wastewater treatment. Ecological Engineering 25(5), 478-490.

Wang, P., Chen, G.Q., 2016. Solute dispersion in open channel flow with bed absorption. Journal of Hydrology 543, 208-217.

Wang, P., Chen, G.Q., 2017. Contaminant transport in wetland flows with bulk degradation and bed absorption. Journal of Hydrology 552, 674-683.

Wang, P., Zeng, L., 2019. On the bicomponent contaminant transport in wetland flow with reactions. Journal of Hydrology 576, 541-550.

Wengrzynek, R.J., 1991. Constructed wetlands to control nonpoint-source pollution. Environment International 20(4), II.

Wu, S., Austin, D., Liu, L., Dong, R., 2011. Performance of integrated household constructed wetland for domestic wastewater treatment in rural areas. Ecological Engineering 37(6), 948-954.

Wu, X.D., Guo, J.L., Chen, G.Q., 2018. The striking amount of carbon emissions by the construction stage of coal-fired power generation system in China. Energy Policy 117, 358-369.

Wu, X.D., Ji, X., Li, C., Xia, X.H., Chen, G.Q., 2019. Water footprint of thermal power in China: Implications from the high amount of industrial water use by plant infrastructure of coal-fired generation system. Energy Policy 132, 452-461.

Wu, X.D., Guo, J.L., Han, M.Y., Chen, G.Q., 2018. An overview of arable land use for the world economy: From source to sink via the global supply chain. Land Use Policy 76, 201-214.

Ye, F., Li, Y., 2009. Enhancement of nitrogen removal in towery hybrid constructed wetland to treat domestic wastewater for small rural communities. Ecological Engineering 35(7), 1043-1050.

Yu, Y., Feng, K., Hubacek, K., 2013. Tele-connecting local consumption to global land use. Global Environmental Change 23(5), 1178-1186.

Zang, Y., Li, Y., Wang, C., Zhang, W., Wei, X., 2015. Towards More Accurate Life Cycle Assessment of Biological Wastewater Treatment Plants: A Review. Journal of Cleaner Production 107, 676-692.

Zhang, B., Chen, G.Q., 2010. Methane emissions by Chinese economy: Inventory and embodiment analysis. Energy Policy 38(8), 4304-4316.

Zhang, B., Zhang, Y., Zhao, X., Meng, J., 2018. Non - CO2 Greenhouse Gas Emissions in China 2012: Inventory and Supply Chain Analysis. Earth's Future 6(1), 103-116.

Zhang, D., Gersberg, R.M., Tan, S.K., 2009. Constructed wetlands in China. Ecological Engineering 35(10), 1367-1378.

Zhang, Q.H., Wang, X.C., Xiong, J.Q., Chen, R., Cao, B., 2010. Application of life cycle assessment for an evaluation of wastewater treatment and reuse project--case study of Xi'an, China. Bioresource Technology 101(5), 1421-1425.

Zhang, T., 2002. Intermittent Activated Sludge Wastewater Treatment Technology and Project Cases. Chemical Industry Press, Beijing (in Chinese).

Zhou, J.B., Jiang, M.M., Chen, B., Chen, G.Q., 2009. Emergy evaluations for constructed wetland and 
conventional wastewater treatments. Communications in Nonlinear Science \& Numerical Simulation 14(4), 1781-1789.

Zhou S.Y., 2010. Low-carbon Ecological Thermodynamic Accounting of Constructed Wetland Engineering for Wastewater Treatment. Doctoral dissertation, University of Peking University (in Chinese).

Zhou, Y., 2008. The Research and Application of the South Seven Wastewater Treatment System. Project Data (in Chinese). 